\title{
Verkürztes Zungenbändchen macht Stillen unmöglich
}

\author{
Mindestens sechs Monate lang \\ sollen Mütter ihre Babys nach der \\ Geburt stillen. Vielen Müttern ist das \\ zu lange. Aber auch bei Frauen, die \\ bereit wären, sich an die Empfehlung \\ zu halten, kann die Durchführung \\ an einer anatomischen Anomalie \\ scheitern.
}

— Ein sog. Zungenbändchen - angeborenes, verdicktes Bindegewebe unter der Zunge - kann die Beweglichkeit der

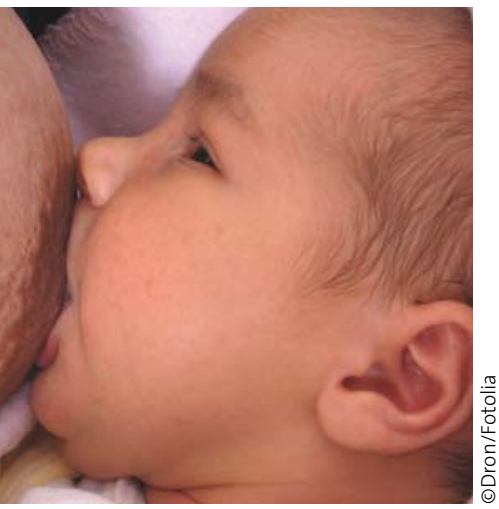

Breast is best - wenn's funktioniert.
Zunge so einschränken, dass der Säugling unfähig ist, an der Mutterbrust ausreichend zu trinken. Schwere Gedeihstörungen können die Folge sein. Die Lösung ist aber ganz einfach.

Ein einfacher Schnitt mit dem Skalpell (bis zum vierten Lebensmonat des Kindes ohne Narkose) beseitigt das Problem. Viele Ärzte scheuen aber vor diesem Eingriff zurück. Dabei ist die Prozedur, Frenotomie genannt, viel einfacher durchzuführen als etwa eine Zirkumzision. Das Ausfüllen der erforderlichen Formulare dauert länger als der Eingriff selbst.

Eine junge Mutter, die schließlich bei den Autoren dieser Arbeit landete, wollte ihr Kind wie empfohlen sechs Monate lang ausschließlich stillen. Bei dem Baby wurde alsbald ein störendes Zungenband festgestellt, das das Stillen erschwerte. Die Mutter erhielt von den Ärzten die Auskunft, sie solle sich keine Sorgen machen, aber das Problem könne nicht vor dem sechsten Lebensmonat beseitigt werden. Kein Arzt würde den erforderlichen Eingriff früher durchführen. Mit sechs Monaten wog das Kind weniger als bei der Geburt. Als die Frenotomie endlich durchgeführt wurde, nahm der Säugling binnen 36 Stunden zwei Pfund an Gewicht zu.

$4,2 \%$ bis $10,7 \%$ aller Neugeborenen sollen an der Anomalie leiden. Bei etwa jedem zweiten entwickeln sich daraus ernsthafte Stillprobleme.

\section{Kommentar}

Die angeborene Anomalie des Zungenbändchens dürfte in Deutschland sicher ähnlich häufig sein wie in den USA. Bei einer jährlichen Geburtenzahl von rund 650000 wären 13000 bis $32500 \mathrm{Neu}$ geborene mit durch Zungenbändchen bedingten Stillproblemen zu erwarten

K. MALBERG -

\footnotetext{
- G. P. Forlenza et al.

Ankyloglossia, exclusive breastfeeding, and failure to thrive. Pediatrics 125 (2010) 1500-1504
}

\section{Haifischknorpel gegen Krebs?}

\begin{abstract}
Haifische bekommen angeblich keinen Krebs. Deswegen sollen Extrakte aus Haifischknorpel in der Onkologie als adjuvante Therapie nützlich sein.
\end{abstract}

- Amerikanische Onkologen randomisierten 379 Patienten mit Lugenkrebs Stadium III in zwei Gruppen. Die Experimentalgruppe erhielt neben der Therapie lege artis einen standardisierten Extrakt aus Haifischknorpel (240 $\mathrm{ml} / \mathrm{Tag}$ ). Die Kontrollgruppe erhielt zusätzlich zur Standardtherapie Placebo.

Die Therapie wurde jeweils bis zum Auftreten von toxischen Nebenwirkungen oder bis zur Progression des Lungenkrebs beigehalten. Die Überlebenszeit galt als Hauptzielparamater. Sie betrug 14,4 Monate in der Verum- und 15,6 Monate in der Kontrollgruppe. Sekundäre Zielvariablen wie die Tumorresponserate zeigten ebenso keine signifikanten Differenzen zwischen den Gruppen. Die Autoren meinen daher, dass der Extrakt bei dieser Patientengruppe nicht wirksam sei.

\section{Kommentar}

Haifischknorpel wird bei vielen Krebspatienten eingesetzt. Ausgangspunkt für die Beliebtheit war die Beobachtung, dass Haifische angeblich keinen Krebs bekommen. Dies erwies sich später als unrichtig. Verblüffenderweise zeigt sich jedoch, dass solche Extrakte in vitro antiangiogene Effekte besitzen, die u. U. bei Krebs wirksam sein könnten. Somit erschien es lohnend, eine klinische Studie zu initiieren.
Die vorliegende Untersuchung ist das lang erwartete Ergebnis dieser Initiative. Sie zeigt überzeugend, dass Haifischknorpel bei Lungenkrebs nutzlos ist. Es ist zu befürchten, dass (wie bei früheren alternativen Krebsmitteln auch) eine Flüsterpropaganda einsetzt und behauptet wird, dass die Studie aus diesem oder jenem Grund mangelhaft sei. Das Ganze hat natürlich das Ziel, eine sehr gut verdienende Industrie auch weiterhin von der verzweiftelten Hoffnung schwerkranker Krebspatienten profitieren zu lassen.

E. ERNST =

\footnotetext{
- C. Lu et al.

Chemoradiotherapy with or without AE-941 in stage III non-small cell lung cancer: A randomised phase III trial. J. Nat. Cancer Inst. 2010 May 26. doi: 10.1093/jnci/djq179
} 